\title{
BISCATINHA: UMA VISÃO DECOLONIAL ACERCA DA MARGINALIDADE IMPOSTA A MENINAS DENTRO DO CONTEXTO DA ESCOLA
}

\author{
BISCATINHA: UNA VISIÓN DECOLONIAL SOBRE LA MARGINALIDAD IMPUESTA \\ A LAS NIÑAS EN EL CONTEXTO ESCOLAR
}

\section{BISCATINHA: A DECOLONIAL VISION ABOUT THE MARGINALITY IMPOSED ON GIRLS WITHIN THE SCHOOL CONTEXT}

\author{
Ana Cláudia Magnani Delle PIAGGE ${ }^{1}$ \\ Tatiane Pereira de SOUZA ${ }^{2}$
}

RESUMO: Esse artigo tem como proposta abordar a discussão do gênero no cotidiano escolar referente ao tratamento dispensado para meninas e mulheres na sociedade. A metodologia utilizada foi a pesquisa bibliográfica sustentada em autores e autoras decoloniais, dos estudos culturais, da diversidade etnicorracial e de gênero nas ciências humanas e sociais, bem como a observação in loco do cotidiano escolar. Nesse sentido, compreendemos que o corpo da menina, dentro da escola, vem sendo educado, conformado, desumanizado para justificar um modelo impositivo de padrões de comportamento e pensamento normativo na sociedade, fato que colabora com o nosso entendimento acerca da urgência em promovermos mais discussões a respeito dessa temática.

PALAVRAS-CHAVE: Educação. Gênero. Mulheres/meninas. Pensamento crítico.

RESUMEN: Este artículo tiene como objetivo abordar la discusión de género en la rutina escolar con relación al trato a las niñas y mujeres en la sociedad. La metodología utilizada fue la investigación bibliográfica basada en autores y autoras decoloniales, los estudios culturales, la diversidad étnico-racial y de género en las ciencias humanas y sociales, así como la observación in situ de la vida escolar. En este sentido, entendemos que el cuerpo de la niña, dentro de la escuela, ha sido educado, conformado, deshumanizado para justificar un modelo imponente de patrones de conducta y pensamiento normativo en la sociedad, hecho que colabora con nuestra comprensión de la urgencia de promover más discusiones sobre este tema.

PALABRAS CLAVE: Educación. Género. Mujeres/niñas. Pensamiento crítico.

ABSTRACT: This article aims to address the discussion of gender in the school routine regarding the treatment of girls and women in society. The methodology used was bibliographic research supported by decolonial authors, cultural studies of ethno-racial and gender diversity

${ }^{1}$ Universidade Estadual Paulista (UNESP), Araraquara - SP - Brasil - SP. Mestranda no Programa de Pósgraduação em Educação Sexual. ORCID: https://orcid.org/0000-0001-6108-6395. E-mail: ana.magnani@unesp.br ${ }^{2}$ Universidade Federal de Uberlândia (UFU), Pontal - MG - Brasil. Professora no Instituto de Ciências Humanas do Pontal/ICHPO. Doutorado em Ciências Sociais (UNESP). ORCID: https://orcid.org/0000-0003-2821-5241. Email: tatiane.akoma@gmail.com

RPGE- Revista on line de Política e Gestão Educacional, Araraquara, v. 24, n. esp. 3, p. 1884-1899, dez. 2020. e-ISSN:1519-9029 
in the human and social sciences, as well as on-site observation of school routine. In this sense, we understand that the girl's body, inside the school, has been educated, conformed, dehumanized to justify an imposing model of standards of behavior and normative thinking in society, a fact that collaborates with our understanding of the urgency to promote more discussions about this theme.

KEYWORDS: Education. Genre. Women/girls. Critical thinking.

\section{Introdução}

Esse artigo trata-se de um convite aos educadores para refletirem sobre uma expressão discriminatória, cunhada histórico e politicamente, e utilizada, com certa frequência, no contexto da escola para apontar meninas dissidentes, que não se enquadram nas normas sociais estabelecidas. Esse comentário machista produz marginalidade contra garotas que desafiam um modelo feminino imposto, não as reconhecendo como sujeitos de sua própria narrativa, fato que contribui para tornar essa palavra uma forte ferramenta de discriminação de gênero.

Para desenvolver estas reflexões, buscaremos nos embasar na corrente do feminismo decolonial por compreender que o colonialismo evidencia um sistema brutal ao qual fomos submetidas e que, ainda hoje, produz uma série de violências, entre elas a psíquica e a discursiva, que assolam ao mulherio. Desse modo, encontramos relevância em tais discussões pois, essas se reproduzem a um nível micropolítico, no dia a dia da escola. Por consequência, vamos referenciar autoras decoloniais, não enquanto teoria somente, mas como práticas políticas transformadoras que nos ajudarão a pensar as meninas enquanto sujeitos situados em contexto. Afinal,

Uma das coisas que aprendi com o feminismo foi a suspeitar de tudo, dado que os paradigmas que são adotados em muitos âmbitos acadêmicos estão sustentados em visões e lógicas masculinas, classistas, racistas e sexistas (CURIEL; GENEROSO, 2019, p. 231).

A proposta aqui consiste em trazer para o debate a palavra biscatinha enquanto fala violenta que tem sido utilizada e com pouca, ou nenhuma, frequência questionada, com o objetivo de promover discussões acerca de temáticas que estão sendo invisibilizadas, promovendo marginalidades e submissão dentro do contexto educativo.

Nesse sentido, além das críticas a um modelo escolar heteronormativo, entendendo a escola como uma instituição que desempenha um papel fundamental na manutenção de um modelo de Estado-Nação e, considerando o Estado-Nação como sendo heterossexual, a partir de um estado heteronormativamente produzido, em sua maioria, por homens em posição de 
poder (CURIEL; GENEROSO, 2019). Assim, buscamos contemplar alguns discursos, que ainda são utilizados no processo educativo como ferramenta de promoção da submissão de corpos a um modelo social e heteronormativo vigente.

Gostaríamos de destacar que não é nosso objetivo com esse trabalho produzir valoração ética e moral dos docentes mas, contribuir para a reflexão de como os termos utilizados, produzidos através de relações imbricadas entre o Colonialismo e o androcentrismo e a falta de reflexões no âmbito das formações de professores, podem manter práticas discriminatórias, que promovem a subalternização de corpos, silenciando vozes e mantendo as relações de poder, sobretudo na opressão do gênero feminino.

\section{A manutenção de uma identidade do feminino}

O Colonialismo diz respeito a uma experiência histórica, do que foi o período Colonial Brasileiro, vivido entre os séculos XVI e XIX. Uma experiência histórica de controle, através da administração política, econômica e cultural baseada em uma relação metrópole e colônia (FANON, 1965). Franz Fanon (1965) evidencia, em sua obra, as consequências psicológicas da colonização, tanto para o colonizador como para o colonizado, evidenciando o fato de que o modelo que se adequa a um determinado povo não, necessariamente, se acomoda a outro, tampouco harmoniza as diferenças.

Desse modo, podemos entender que os modos de 'ser mulher' na metrópole não podem ser considerados os mesmos em outros espaços ou, como diz Fanon (1965), na colônia. Que as formas de produção da existência comuns a espaços coloniais, não podem ser copiados por outros territórios nos quais coexistem a diversidade de experiências, tais como favelas, comunidades de povos originários, quilombos, periferias urbanas, entre outros. Nesse sentido, as inúmeras formas de 'ser mulher' se misturam através de uma multiplicidade de vozes, expressando outras cosmovisões de mundo, que vão desde a forma de dançar, de se vestir até a forma de se expressar, sentir.

As muitas formas de fazer-se mulher ou homem, as várias possibilidades de viver prazeres e desejos corporais são sempre sugeridas, anunciadas, promovidas socialmente (e hoje possivelmente de formas mais explícitas do que antes). Elas são também, renovadamente, reguladas, condenadas e negadas. Na verdade, desde os anos sessenta, o debate sobre as identidades e as práticas sexuais e de gênero vem se tornando cada vez mais acalorado, especialmente provocado pelo movimento feminista, pelos movimentos de gays e de lésbicas e sustentado, também, por todos aqueles e aquelas que se sentem ameaçados por essas manifestações. Novas identidades sociais tornam-se visíveis, provocando, em seu processo de afirmação e 
diferenciação, novas divisões sociais e o nascimento do que passou a ser conhecido como "política de identidades" [Stuart Hall, 1997] (LOURO, 1999, p. 9-10).

Em 2020, coexistem no Brasil altos índices de conservadorismo, repressão sexual, discriminação e desrespeito as diferenças entre as pessoas. Tudo isso nos provocando a pensar sobre a necessidade de a escola abarcar discussões acerca de uma 'cultura sexual brasileira', expressa através dos discursos oficiais e a forma múltipla e diversa, com que o povo brasileiro entende e vive a sua sexualidade, em seus diferentes territórios.

Eagleton (2011) propõe a superação do conceito de cultura para além de seus sentidos estéticos e antropológicos, considerando-a como 'questões do espírito' em uma definição filosófica para o conceito. Consideramos essa proposição adequada para a reflexão sobre a forma como o feminismo entende 'cultura', sendo o modo como a sociedade permite, tolera ou, mesmo, banaliza violências sofridas, tornando sua vítima culpada pela violência sofrida. Uma 'questão do espírito'.

Desse modo, ao nos referirmos a uma ideia de 'Cultura Sexual Brasileira' estamos querendo abarcar todo um imaginário formado sobre a sexualidade que se manifesta nos comportamentos, nas atitudes e nas práticas sexuais, variando em tempos históricos diferentes, porém, forjadas desde o início da existência do nosso povo.

Uma 'Cultura Sexual' enquanto uma experiência relacionada a verdades políticas historicamente construídas, promovendo sentidos e valores morais que proporcionam os saberes, as normas e as subjetivações a que estão submetidos os corpos (FOUCAULT, 1984).

Com esse entendimento a respeito do conceito cultura que utilizaremos para fim das discussões propostas nesse trabalho, buscaremos refletir sobre a construção histórica e social de um 'ser menina' que através de interpretações equivocadas produz uma expressão discriminatória, utilizada com frequência no contexto da escola para apontar meninas dissidentes, que não se conformam as normas sociais estabelecidas. Um comentário machista, cunhado ao longo da trajetória histórica brasileira, que produz, na atualidade, marginalidade contra as garotas que desafiam um modelo feminino imposto, por ser uma forte ferramenta de discriminação.

Devemos apontar o fato de que, eventualmente, quando um pesquisador toma o caminho dos estudos de 'minorias', ou mais especificamente, os estudos que se referem às violências simbólicas impostas a jovens mulheres, meninas, através de expressões discriminatórias, acaba por se deparar com um silenciamento ou uma escassez nas fontes. Fato que parece apontar para 
a manutenção de uma ausência de discussões acerca da repercussão das experiências vivenciadas na infância como sendo capazes de impactar a formação da futura mulher.

Mantidas à margem da história, meninas continuam a ser subestimadas ou consideradas de pouca importância. Porém, não podemos prescindir da responsabilidade de fazer emergir as violências impostas a elas, principalmente na forma do discurso, que imerso em relações de poder, produz inferioridade e subalternidade, sendo utilizada de forma naturalizada, até mesmo no espaço da escola.

Biscatinha é um termo que reflete uma realidade violenta. Por vezes, o seu emprego tem por finalidade a manutenção de estruturas patriarcais e machistas, como refletiremos a frente. Com frequência, porém, a utilização desta palavra, dentro do contexto da escola, é considerada um fenômeno menor, sem importância, apesar de servir ao propósito de manter a ordem da estrutura estabelecida. Uma expressão que mantém uma ordem.

A palavra biscatinha, traz como pano de fundo a marginalidade, o machismo e a violência. A singularidade da nossa reflexão reside, justamente, em evidenciar que mesmo inconscientemente, a escola, enquanto uma instituição com a função educacional, não é capaz de ser desafiada pelas contradições e demandas suscitadas por uma sociedade cada vez mais plural. A escola, para o pesquisador José Manuel Moran (2014), é uma das instituições mais resistentes à mudança, fato que colabora com a manutenção de injustiças e preconceitos. Nesse sentido, podemos dizer que a escola é capaz de produzir atos violentos, que apesar de não causarem morte ou destruição física, são capazes de aniquilar a auto estima de uma pessoa. Tudo ocorrendo, em seu espaço, de forma naturalizada.

Corroborando com essa análise, Nilma Lino Gomes considera que,

Muito se tem discutido sobre a importância da escola como instituição formadora não só de saberes escolares como, também, sociais e culturais. Tendo isso em vista, alguns estudiosos do campo da educação e da cultura têm destacado o peso da cultura escolar no processo de construção das identidades sociais, enfatizando a escola como mais um espaço presente na construção do complexo processo de humanização (ARROYO, 2000; BRUNER, 2001). Por essa perspectiva, a instituição escolar é vista como um espaço em que aprendemos e compartilhamos não só conteúdos e saberes escolares, mas também valores, crenças, hábitos e preconceitos raciais, de gênero, de classe e de idade (GOMES, 2002, p. 40).

Desse modo, talvez tenha se tornado previsível que a escola reproduza modelos de comportamento e de beleza, do que é considerado certo ou aceitável, dentro de determinados padrões já instituídos por grupos hegemônicos. Modelos que se afastam da realidade de um espaço ocupado por diferentes grupos sociais e culturais. Em vista disso, torna-se legítimo 
perguntar-nos sobre o papel que a escola desempenha na formação de identidades e subjetividades de meninas, de modo a compreender e superar os desafios impostos por uma sociedade preconceituosa e hostil.

Em Arendt (1999), a temática do mal não se encontra atrelada a malignidade, mas em evidenciar que nós, humanos, podemos realizar ações maldosas, que chegam a causar destruição, sem sequer compreendermos essas como ações malignas. A autora considera que ocorre a naturalização por parte da sociedade das posturas e ações, de forma massificada e tecnificada. A maldade torna-se, não mais condenável através de uma visão moral ou religiosa, mas aceitável na perspectiva ética-política. Uma forma de governar sustentada por um método que prevê a descartabilidade humana daqueles que são considerados inadequados através do discurso. Mas, como são construídos esses discursos?

\section{A história do colonialismo e sua relação com a manutenção de uma estrutura hierárquica de gênero desde a infância}

Expomos nesta parte do trabalho o entendimento de que o corpo e o lugar a ser ocupado pela menina em nossa sociedade se constrói, também através da educação formal, por meio daquilo que lhe é ensinado e do que lhe é negado saber. O silenciamento histórico das relações de gênero no período colonialista pode ser uma potente ferramenta na manutenção de discursos machistas, arraigados em um modelo patriarcalista, que ampliam as desigualdades e as violências contra as mulheres. A escola, nesse sentido, tem a obrigação de promover discussões, através de aulas de história decolonizada, como forma de enfrentamento a estrutura de gênero e racial firmada no Brasil.

Os portugueses, ao invadirem o Brasil em 1500, se depararam com povos originários habitando essas terras. Não uma terra desabitada ou ocupada por 'povos selvagens' (termo cunhado para indicar a ausência de modos civilizados como entendido pelos colonizadores europeus), mas por uma sociedade indígena detentora de uma cultura própria que se diferenciava dos costumes predominantes no corpo social português. Porém, os dominadores não entendiam desse modo, olhando com estranheza para os costumes manifestados pelos indígenas.

Vemos que os livros didáticos trazem uma outra descrição para o momento de encontro da cultura europeia com a cultura dos povos originários de nosso continente, nomeada de 'descobrimento'. Essa reprodução de uma ideia equivocada a respeito do início de nossa 
colonização produz, nos estudantes, a formação de um falso imaginário de relações firmadas de forma harmônica.

María Lugones (2014), em seu artigo Rumo a um feminismo decolonial, vai refletir acerca das questões relacionadas a gênero em termos de 'colonialidade de gênero', por compreender que as formas como as relações de gênero e sexualidade são impostas e significadas no norte do mundo atendem a uma construção de gênero eurocêntrica.

Começando com a colonização das Américas e do Caribe, uma distinção dicotômica, hierárquica entre humano e não humano foi imposta sobre os/as colonizados/as a serviço do homem ocidental. Ela veio acompanhada por outras distinções hierárquicas dicotômicas, incluindo aquela entre homens e mulheres. Essa distinção tornou-se a marca do humano e a marca da civilização. Só os civilizados são homens ou mulheres. Os povos indígenas das Américas e os/as africanos/as escravizados/as eram classificados/as como espécies não humanas - como animais, incontrolavelmente sexuais e selvagens. O homem europeu, burguês, colonial moderno tornou-se um sujeito/ agente, apto a decidir, para a vida pública e o governo, um ser de civilização, heterossexual, cristão, um ser de mente e razão (LUGONES, 2014, p. 936).

Uma aula de história crítica e reflexiva poderia proporcionar aos alunos uma discussão sobre as cartas de 'achamento' redigidas por Pero Vaz de Caminha (s/d). Nelas, os portugueses, descrevem o seu espanto, por exemplo, em relação a nudez dos indígenas. Nessas cartas eles se referem a esses indivíduos como machos e fêmeas, pôr os considerarem 'selvagens', se distanciando dos termos homem e mulher utilizados no mundo 'civilizado' para distinguir os gêneros. Ou seja, ser homem e ser mulher são ideais coloniais morais a serem conquistados, parte de um processo e um projeto de civilização. A importância dessa discussão no âmbito da escola se torna relevante à medida em que descreve indivíduos como 'macho' e 'fêmea', aproximando esses indivíduos da selvageria, parte de um mundo natural assim como os outros animais avistados, promovendo a animalização desses sujeitos.

Começo, então, com uma necessidade de entender que os/as colonizados/as tornaram-se sujeitos em situações coloniais na primeira modernidade, nas tensões criadas pela imposição brutal do sistema moderno colonial de gênero. Sob o quadro conceitual de gênero imposto, os europeus brancos burgueses eram civilizados; eles eram plenamente humanos. A dicotomia hierárquica como uma marca do humano também tornou-se uma ferramenta normativa para condenar os/as colonizados/as. As condutas dos/as colonizados/as e suas personalidades/almas eram julgadas como bestiais e, portanto, não gendradas, promíscuas, grotescamente sexuais e pecaminosas. Mesmo que nesse tempo a compreensão do sexo não fosse dimórfica, os animais eram diferenciados como machos e fêmeas, sendo o macho a perfeição, a fêmea a inversão e deformação do macho. [...] A missão civilizatória, incluindo a conversão ao cristianismo, estava presente na concepção ideológica de conquista e 
colonização. Julgar os/as colonizados/as por suas deficiências do ponto de vista da missão civilizatória justificava enormes crueldades. Proponho interpretar, através da perspectiva civilizadora, os machos colonizados não humanos como julgados a partir da compreensão normativa do "homem", o ser humano por excelência. Fêmeas eram julgadas do ponto de vista da compreensão normativa como "mulheres", a inversão humana de homens. Desse ponto de vista, pessoas colonizadas tornaram-se machos e fêmeas (LUGONES, 2014, p. 936-937).

Uma história decolonizada proporciona aos alunos a possibilidade de compreender que o gênero, ou aquilo que nós entenderemos como diferença sexual, surge na América Latina e em outras terras colonizadas como uma diferença animal e não como uma diferença de gênero. Proporcionando aos alunos um olhar crítico sobre as falas produzidas. De uma forma interdisciplinar, a citação de Simone de Beauvoir (1967) 'Ninguém nasce mulher, torna-se mulher', assume a possibilidade de, a partir da inserção nesse contexto colonialista, questionar o modo como o pensamento eurocêntrico se impõe sobre o mundo com a definição de ser mulher. Pois, ser homem e ser mulher, de acordo com esse entendimento, era algo a ser alcançado a partir da inserção em uma determinada cultura, dita civilizada.

Ouvimos também referências às mulheres indígenas e a forma como estas manifestavam um certo 'empoderamento' em relação às mulheres da Europa e que a liberdade sexual era bastante significativa, pois as índias não tinham os pudores cristãos que eram vigentes na Europa. Tal discurso demonstra a necessidade de uma educação que supere as assimetrias causadas por uma visão estereotipadas acerca das mulheres indígenas.

A nudez das mulheres indígenas não tinha a ver com liberdade sexual, mas com uma cosmovisão de mundo própria acerca dos corpos. Quando desconsideramos essas diferenças estamos, na verdade, reproduzindo lógicas coloniais e etnocêntricas.

Gilberto Freyre (1968), em seu livro Casa Grande \& Senzala, nos relata a vinda para o Brasil de sujeitos 'degredados', entre estes, 'numerosos indivíduos' acusados de 'tocamentos desonestos'. Podemos entender que para o Brasil eram enviados numerosos estupradores em potencial. Agora, vamos imaginar esses sujeitos aportando em terras brasileiras e se deparando com mulheres indígenas nuas e inocentes.

Será que podemos considerar que nesse momento histórico começa a se formar uma cultura de culpabilização das vítimas de estupro? Afinal, essas mulheres indígenas não se encontravam vestidas. Consideramos essa uma excelente pergunta norteadora para desencadear reflexões por parte dos alunos. 
Existem poucos relatos históricos, do ponto de vista da história oficial no interior das instituições, sobre a forma como era o comportamento do homem branco em relação às mulheres indígenas e negras.

Marina Basso Lacerda (2010), vai citar em sua tese, o bandeirante Domingos Jorge Velho, conhecido erroneamente, segundo Carneiro (1958), como matador de Zumbi e destruidor do Quilombo dos Palmares no século XVII, como um abusador, que forçava as mulheres que encontrasse pelo caminho, além de manter, para seu desfrute, sete concubinas índias.

Os portugueses chegaram às terras que hoje chamamos de Brasil como conquistadores, se apossando de tudo que quisessem, a seu bel prazer. O que se interpusesse em seu caminho deveria ser eliminado. E assim fizeram. Dizimaram indígenas, estupraram mulheres, saquearam a terra.

Se instalava aqui uma cultura colonialista. Uma experiência histórica, concreta, aterradora que se estendeu do século XVI ao XIX. Uma realidade histórica, de controle e dominação, que se estendia aos âmbitos político, econômico, simbólico, religioso e cultural, inclusive, no âmbito sexual.

As formas como as relações de gênero e sexualidade foram impostas e significadas no Brasil atenderam a essa construção de gênero eurocêntrica, na qual as relações de poder são mediadas pelo gênero.

As relações de poder chegaram aqui de uma forma impositiva. Os nativos tiveram suas formas de organizar e de pensar as relações de gênero e sexualidade apagadas, destruídas. Pois, precisamos compreender que nesse embate, as dinâmicas de poder promovidas durante a colonização, se apropriaram e corromperam todas as organizações de sistemas locais, de corporeidades, de organizações semelhantes a estruturas familiares e de organização das diferenças. Os portugueses chegaram aqui impondo suas concepções cristãs europeias.

Com o avanço da colonização, a escravização se tornou outra prática presente nesse sistema. Com a escravização, as escravizadas africanas, foram desumanizadas e submetidas às práticas sexuais de seus senhores.

Persiste em nossa cultura um apagamento de tudo que possa ser considerado desagradável. Um exemplo disso podemos ver nas páginas da celebre obra Casa Grande \& Senzala, que apesar da óbvia tentativa em promover um ideário de consentimento mútuo nas relações estabelecidas entre brancos e negros, traz algumas histórias degradantes em suas páginas. 
Gilberto Freyre (1968), relata as anotações do médico João Álvares Macedo Junior, que em 1869, citava um estranho costume. "A inoculação deste vírus em uma mulher púbere é o meio seguro de o extinguir em si."

Foram os senhores das casas-grandes que contaminaram de lues (sífilis) as negras das senzalas. Negras tantas vezes entregues virgens, ainda mulecas de 12 e 13 anos, a rapazes brancos já podres da sífilis das cidades. Porque por muito tempo dominou no Brasil a crença de que para o sifilítico não há melhor depurativo que uma negrinha virgem (FREYRE, 1968, p. 338).

Joaquim Nabuco (1988), em seu livro A escravidão, considera que as mulheres negras, escravizadas, eram utilizadas para o prazer sexual e para a "reprodução do cativeiro", em um abuso e estupro desenfreado dessas mulheres.

Nunca houve consenso. Mas sim, sofrimento e dor. O estupro era a prática cotidiana, corriqueira e impune. Nosso país nasceu da prática do estupro. Aqui se estuprou pessoas e culturas, uma prática colonialista ainda vigente, ainda naturalizada como prática do direito masculino, principalmente do homem branco. Nesse sentido, uma educação que se considere crítica, não pode se furtar a oferecer discussões embasadas em uma história decolonizada. A cultura do estupro estabelecida através da Colonialidade, continua preservada através dos silenciamentos e invisibilizações de verdades históricas. As relações estabelecidas entre homens e mulheres, brancos, negros e indígenas se conservam romantizadas através dos livros didáticos

A violência sexual contra a mulher está enraizada em nossa história, pois devemos compreender que o direito sobre o corpo da mulher se estabeleceu através de um direito patriarcal. Marina Lacerda (2010) aponta o senhor da terra como o agente da colonização e do estupro. Esse fato irá possibilitar a falta de punição, pois em um sistema colonial, a mulher (sobretudo a mulher negra e indígena) é considerada propriedade e, como parte do patrimônio, qualquer violação não pode ser considerada abuso, mas sim manutenção de uma ordem e de um status quo. A violência de gênero atesta o lugar de poder em que se ocupa o opressor, assim, podemos inferir para outras lógicas de dominação e poder, sejam elas de ordem racial, religiosa etc.

Desse modo, consideramos que uma história brasileira crítica irá apontar para o fato de que a mulher indígena foi a primeira vítima nesse processo histórico, sendo sexualmente abusada e escravizada. As mulheres negras, escravizadas, foram vítimas de violações generalizadas. Uma cultura em que o abuso sexual ocorria em nome do prazer e da 'reprodução do cativeiro'. Uma história das relações sexuais invisibilizadas, que nega o sadismo do 
colonizador em relação aos seus subalternizados, do homem branco sobre os indivíduos negros e indígenas, do homem branco europeu sobre todas as mulheres da colônia.

Todo esse apagamento histórico nos faz refletir sobre como podemos pensar em uma eficiente educação sexual nas escolas, se mantemos em nossos currículos somente uma visão eurocêntrica da história com um apagamento de grande parte da nossa história, tanto como país como parte de um continente. Uma invisibilização de processos históricos que promoveram a efetivação de uma cultura de estupro no Brasil e da culpabilização de suas vítimas.

A educação pode tecer um paralelo entre a época da escravização e a atualidade, na qual se encontra mantido um ideário de homem como proprietário da mulher, nunca parte de uma relação entre iguais, entre pessoas.

Todo esse contexto nos leva a pensar a necessidade de trazer essa discussão de modo urgente nos âmbitos escolares da educação básica até a pós graduação nesse país, não somente para erradicar o que está posto como violência de gênero, mas sobretudo para preveni-la.

\section{A conformação do corpo da menina através da educação}

Através do exposto entendemos que a escola se torna uma das instituições responsáveis pela manutenção de um sistema colonialista e de reprodução de normas de gênero a medida em que não questiona o papel que desempenha na reprodução do gênero. Pois, após toda a nossa reflexão queremos questionar: Como a educação pode promover a emancipação de seus sujeitos se ao posicionar-se sobre o que é 'ser menina' continua reproduzindo discursos colonialistas?

Vieira (2020) nos provoca a pensar. Para esse modelo de escola vigente, o que significado 'ser menina'? Como esse corpo torna-se uma menina? E isso poderá significar tudo que esse alguém é? 'Ser menina' é de fato alguma coisa ou existe um percurso de outra ordem, histórica, social, política, que constituiria uma idealidade do que deve ser uma menina e que as impeliria, através da insistente interpelação do poder, a agir segundo o que se diz 'ser menina'.

Visto que, segundo a transfeminista Helena Vieira (2020), esses corpos não escapam do poder mesmo que manifestem uma pretensa condição de liberdade, pois essa se expressará como uma condição de poder, já que somos constituídos pelo poder. É o poder que nos constitui como sujeitos, o mesmo poder que nos sujeita. Esse poder que nos sujeita é o que nos faz ser sujeitos. Justamente por isso chama-se sujeição. Porque não é só o ato de se tornar sujeito, mas, também, o ato de sujeitar-se.

Esse imaginário de um 'ser menina' que serve como parâmetro para mensurar todas as formas de ser nos é imposta através de um modelo hegemônico de colonialidade. Padrão 
colonialista esse que, por meio de práticas conservadoras, vem mantendo por meio da educação, dentro e fora das instituições escolares, os padrões de subalternização e violência contra as mulheres, iniciado desde a socialização do gênero que antecede ao nascimento da criança, neste caso, das meninas. A expressão isso é coisa de menina, de menininha, comumente falado por familiares, pais, mães e docentes, já diz muito sobre como a subjugação do corpo feminino e de tudo que se associa ou refere a ele é tratado. Um tratamento desigual e inferiorizado, isso permanece na memória coletiva da sociedade e é atualizado nas relações sociais; uma educação que se pretende descolonizada, precisa romper com essa lógica.

Exemplificando: quando nos referimos a uma menina dizendo: esse não é o comportamento adequado a uma menina estamos, na verdade, a analisando a partir de normas morais impostas, quando na verdade, 'ser menina' é uma constituição física. Para além disso, estamos categorizando sua existência através de condutas específicas do que significa, dentro de uma determinada cultura, 'ser menina', baseado em compreensões sociais e culturais colonialistas.

Mas podemos perguntar, de onde vem as normas morais impostas que norteiam a forma como compreendemos o 'ser menina'? Que normas orientam o currículo e a prática dentro do ambiente escolar que reforçam tais condutas?

É preciso considerar e ressaltar, mais uma vez, que a escola é parte da estrutura social e que em certa medida tende a reproduzir o que se produz nas relações sociais, inclusive a violência e os desígnios das desigualdades sociais. Por isso, a escola também contribui para aquilo que as pessoas tendem a se tornar. O que a escola anda produzindo desse ponto de vista? A escola está produzindo mulheres emancipadas, alienadas ou oprimidas?

Simone de Beauvoir (1967) compreende o 'ser mulher' como uma consequência de um longo processo de formação e conformação a um modelo social e cultural, no qual são impressas as "marcas, $[\ldots]$ gestos, $[\ldots]$ comportamentos, $[\ldots]$ preferências e $[\ldots]$ desgostos $[\ldots]$ ensinados e reiterados, cotidianamente, conforme normas e valores de uma dada cultura" (LOURO, 2008, p. 17). Todavia, o que não nos questionamos é de qual cultura vem essa lógica que nos é imposta?

Devemos considerar que Simone de Beauvoir (1967) escreve a partir de um lugar ocupado por uma hegemonia intelectual, em um dos países mais ricos da Europa. Neste sentido, o saber produzido, através de uma lógica hierarquizante, ocupa um lugar de mais valia se sobrepondo a outros saberes, fato que ocorre por conta de uma lógica de colonialidade.

É claro, não devemos desconsiderar sua obra ao proceder estudos acerca da temática do feminismo, mas ao estudá-la devemos nos manter atentas para questionar ou refletir sobre o 
fato de como sua obra se impõe como definição do feminino ou do 'ser mulher', imposta por meio de uma lógica da colonialidade. Pois, entendemos que essa lógica não dá conta em abarcar toda a variedade de condições de vida dessas mulheres, tão pouco, dos processos que envolvem o se constituir mulher, os distanciando de sua real humanidade.

Além disso, podemos refletir que,

A primeira objeção forte de Butler a Beauvoir é que, caso se aplique consistentemente a distinção sexo/gênero, a explicação beauvoiriana não permite ver com clareza se um sexo dado torna-se necessariamente (causalmente) um gênero determinado. Porque, se ser mulher é uma interpretação cultural de ser fêmea (female), então, segundo Butler, pode-se concluir que não é qualquer corpo que é arbitrariamente o locus do gênero "mulher", mas sim um corpo já definido previamente para tal efeito (BUTLER, 1986, p. 37). Nesse sentido, a distinção sexo/gênero implicaria uma heteronomia radical dos corpos naturais e os gêneros se construiriam de modo tal que "ser fêmea" e "ser mulher" seriam duas formas diferentes de "ser". O verbo copulativo "ser" asseguraria uma relação fixa e idêntica, à maneira de disjuntivas excludentes. Entretanto, continua Butler, nunca se é mulher num mesmo sentido: tal identidade não é possível. Ao contrário, se, por definição, o gênero é a variável cultural que interpreta o sexo, carece ele de firmeza e deixa em aberto as características interpretativas da identidade. Por isso, ser um gênero (homem, mulher ou, em termos de Butler, paródico) é sobretudo estar comprometida/o com uma interpretação cultural no uso dos corpos, posicionada/o dinamicamente em um campo de possibilidades culturais (FEMENÍAS, 2012, p. 315-316).

Diante disso, segundo Femenías (2012), podemos propor o questionamento a partir do que reflete Butler (1986): Mesmo que gênero pudesse ser impresso sobre um corpo, esse seria um agente meramente passivo? De que forma esse gênero se inscreve sobre esse corpo inerte? Pois, para a autora, Beauvoir não dá conta de explicar a forma como ocorre o estado de dependência desse corpo a uma reprodução de gênero. Nem é de fato o que a autora tem como função, mas pensando a partir da educação, como ciência que se preocupa com a formação e aprendizagem humana, é mister preocupar-se com processos educativos, situados em práticas sociais, que desencadeiam aprendizagens que rompam com essa lógica de dominação do corpo da mulher, enclausurado pelo sociedade no laço do patriarcado ocidental.

Em um mundo ocidentalizado o papel de mulher implica uma série de desafios impostos por relações de poder e sentidos produzidos por essas. Binômios hierarquizantes tais como 'civilizado’ x ‘incivilizado', ‘sujo’ x 'limpo', 'certo’ x ‘errado'. Práticas de poder engendradas pelo Colonialismo que não dependem das qualidades da pessoa e que mantêm aqueles que ousam manifestar comportamentos que destoam das normas impostas, sistematicamente sujeitos a violência de um modelo opressor. Um processo que ocorre por meio da 
interseccionalidade, dos atravessamentos promovidos pelos conceitos raça, classe social e gênero. Um processo não uniforme, plural, não estático.

Por consequência, um processo sujeito a um sistema de opressões que tornam invisíveis ou marginais outras formas de existência que não aquelas que se encaixam nos padrões de gênero hegemônicos, as que são estabelecidos a partir de mecanismos de poder (FOUCAULT, 2004). À vista disso, pensar como as opressões se combinam e se entrecruzam, gerando outras formas de opressão, é fundamental para se pensar outras possibilidades de existência.

$\mathrm{Na}$ atualidade, meninas de todas as classes sociais tem se tornado parte das revoluções pelas quais a sociedade contemporânea tem passado, manifestando modos de comportamentos considerados ousados, na forma de se vestir, se comportar, confrontando uma visão estereotipada da mulher submissa existente no imaginário social, como um papel ideológico legitimado pela tradição histórica colonial.

O modelo de escola que reproduzimos ainda espelha o modelo colonial machista, mantendo um modelo idealizado de 'boas meninas'.

O historiador Stuart Schwartz (1988) chama atenção para o fato de que, nas estratégias das famílias abastadas do Brasil Colonial, a escolha de uma esposa certa era fundamental. Era uma resolução familiar sem a participação da mulher. O matrimônio tinha um significado de união patrimonial. E os interesses econômicos, financeiros e de alianças políticas entre as famílias que se uniam, como era a reprodução do que ocorria na nobreza europeia. As mulheres para casar recebiam um dote. $\mathrm{O}$ seu valor dependia a qualidade da união que essa mulher poderia alcançar.

$\mathrm{Na}$ atualidade, um imaginário construído durante o período colonial continua classificando como 'boas meninas' aquelas que se comportem de forma recatada e silenciosa. Meninas 'boas' para casar. Desse modo, as 'outras' devem ser consideradas desfrutáveis, namoradeiras, vadias, atendendo igualmente ao mesmo imaginário construído historicamente e reproduzido através da instituição familiar e escolar. Nesse âmbito, os discursos preconceituosos e machistas assumem o sentido de conformação a norma, suscitando produções de pensamentos e posturas que atendam às regras sociais. Nesse sentido, infelizmente homens produzem o machismo e muitas mulheres, devido a educação envenenada pelo patriarcado, tendem a reproduzi-lo sem nem sequer exercer um pensamento crítico sobre aquilo que se diz contra mulheres e meninas. Uma postura acrítica diante da realidade.

Ademais, devemos considerar, a partir do entendimento de Franz Fanon (2008), sobre a condição de 'outro', que a mulher, em uma sociedade dominada por um modelo machista, assume a condição de 'outro'. Outro que o não 'ser homem', portanto, passível de submissão 
ao seu sistema de interpretação e de domínio. Um 'ser homem' que objetifica o corpo feminino, desde a infância, tornando-o obediente aos seus desejos e a sua visão de mundo.

O corpo da menina, dentro da escola, está sendo educado, conformado, desumanizado para justificar um modelo impositivo em padrões de comportamento e pensamento normativo na sociedade.

\section{REFERÊNCIAS}

ARENDT, H. Eichmann em Jerusalém: um relato sobre a banalidade do mal. Trad. José Rubens Siqueira. São Paulo: Companhia das Letras, 1999.

BEAUVOIR, S. O segundo sexo: a experiência vivida. São Paulo: Difusão Europeia do Livro, 1967.

BRASIL. Ministério da Cultura. A carta de Pero Vaz de Caminha. s/d. Disponível em: http://objdigital.bn.br/Acervo_Digital/livros_eletronicos/carta.pdf. Acesso em: 15 ago. 2020.

BUTLER, J. O que é a crítica? Um ensaio sobre a virtude de Foucault. Trad. Gustavo Hessmann Dalaqua. Cadernos de ética e filosofia política, n. 22, p. 159-179, 2013.

CARNEIRO, E. O quilombo dos palmares. São Paulo: Companhia Editora Nacional, 1958.

CURIEL, O; GENEROSO, L. M. A. Crítica pós-colonial a partir das práticas políticas do feminismo antirracista. Revista De Teoria Da História, v. 22, n. 2, p. 231-245, 2019. Disponível em: https://www.revistas.ufg.br/teoria/article/view/58979. Acesso em: 19 ago. 2020.

EAGLETON, T. A ideia de cultura. Trad. Sandra Castello Branco. São Paulo: Editora UNESP, 2011.

FANON, F. Os condenados da terra. Lisboa: Editora Ulisseia, 1965.

FANON, F. Pele negra, máscaras brancas. Trad. Renato da Silveira. Salvador: EDUFBA, 2008.

FEMENÍAS, M. L. A crítica de Judith Butler a Simone de Beauvoir. Sapere Aude, Belo Horizonte, v. 3, n. 6, p. 310-339, 2012.

FOUCAULT, M. História da sexualidade 2. Trad. Maria Thereza da Costa Albuquerque. Rio de Janeiro: Edições Graal, 1984.

FOUCAULT, M. Microfísica do poder. 23. ed. São Paulo: Graal, 2004.

FREYRE, G. Casa grande \& senzala: formação da família brasileira sobre o regime da economia patriarcal. 24. ed. São Paulo: Círculo do Livro, 1968. 
GOMES, N. L. Trajetórias escolares, corpo negro e cabelo crespo: reprodução de estereótipos ou ressignificação cultural? Rev. Bras. Educ., Rio de Janeiro, n. 21, p. 40-51, dez. 2002. DOI: http://dx.doi.org/10.1590/S1413-24782002000300004

LACERDA, M. B. Colonização dos corpos: ensaio sobre o público e o privado.

Patriarcalismo, patrimonialismo, personalismo e violência contra as mulheres na formação do Brasil. Orientador: Carlos Alberto Plastino. 2010. 114 f. Dissertação (Mestrado em Direito) Pontifícia Universidade Católica do Rio de Janeiro, Rio de Janeiro, 2010. Disponível em: https://www.maxwell.vrac.puc-rio.br/colecao.php?strSecao=resultado\&nrSeq=16570@1. Acesso em: 26 ago. 2020.

LOURO, G. L (Org.). O corpo educado: pedagogias da sexualidade. Trad. Tomaz Tadeu da Silva. Belo Horizonte: Autêntica, 1999.

MORAN, J. M. A educação que desejamos, novos desafios e como chegar lá. Papirus Editora, 2014.

SCHWARTZ, S. B. Segredos internos: engenhos e escravos na sociedade colonial, 15501835. São Paulo: Companhia das Letras, 1988.

SPIVAK, G. C. Pode o subalterno falar? Trad. Sandra Regina Goulart Almeida, Marcos Pereira Feitosa e André Pereira Feitosa. Belo Horizonte: Editora UFMG, 2010.

VIEIRA, H. Introdução ao pensamento de Judith Butler. Evento Sympla, ago./set. 2020. Curso on line, evento encerrado. Planejamento e organograma disponíveis em: https://www.sympla.com.br/introducao-ao-pensamento-de-judith-butler-com-helenavieira_940972. Disponível em: 9 out. 2020.

\section{Como referenciar este artigo}

PIAGGE, A. C. M. D.; SOUZA, T. P. Biscatinha: uma visão decolonial acerca da marginalidade imposta a meninas dentro do contexto da escola. Revista on line de Política e Gestão Educacional, Araraquara, v. 24, n. esp. 3, p. 1884-1899, dez. 2020. e-ISSN:1519-9029. DOI: https://doi.org/10.22633/rpge.v24iesp3.14446

Submetido em: 10/01/2020

Revisões requeridas: 20/07/2020

Aprovado em: 30/10/2020

Publicado em: 30/11/2020 